\title{
A case of Polymicrogyria with Alpha Dystroglycanopathy presented with milder form with intellectual disability and partial seizure
}

\author{
Dr Ranjan Bhattacharyya MD, DNB${ }^{1}$, Dr Supriya Kumar Mandal MD², Dr Barindranath Mallick \\ $\mathrm{MD}^{3}$, Dr Sumita Bhattacharyya DDVL ${ }^{4}$, Dr Utpal Ray MD', Dr Jayashree Bhattacharyya MD $^{6}$
}

Assistant Professor \& Head of the Department, Deptt of Psychiatry, Murshidabad Medical College \& Hospital, West Bengal, India ${ }^{1}$

Assistant Professor, Deptt of Psychiatry, Murshidabad Medical College \& Hospital, West Bengal, India ${ }^{2}$ Assistant Professor, Deptt of Radiology, Murshidabad Medical College \& Hospital, West Bengal, India ${ }^{3}$ Medical Officer (Dermatology), Lalbagh Sub-divisional Hospital, Murshidabad, West Bengal, India ${ }^{4}$ Assistant Professor, Deptt of Anesthesiology, Murshidabad Medical College \& Hospital, West Bengal, India ${ }^{5}$ Assistant Professor, Deptt of Pathology, Murshidabad Medical College \& Hospital, West Bengal, India ${ }^{6}$

\section{ABSTRACT}

Keywords : Alpha dystroglycanopathy; complex partial seizures; fukutin; polymicrogyria; developmental delay.

Background : Congenital muscular dystrophy (CMD) refers to a group of muscular dystrophies that become apparent in early infancy or at birth. Muscular dystrophies are mostly genetic and a degenerative disease primarily affects voluntary muscles.

Introduction: Alpha dystroglycanopathies both phenotypically and genetically are heterogeneous group of disorders and a subgroup of these patients has characteristic brain imaging findings. Material and methods: The case vignette shows a four year old girl presented in the OPD with history of throwing tantrums, delayed developmental milestones, irritability and anger outbursts. She had a history of admission in paediatric neurology indoor with complex partial seizures controlled by tab oxcarbazepine. She was born full term of non-consanguineous marriage by LUCS. There was progressive muscular weakness since early infancy with difficulty in sucking and breathing. No developmental regression was noticed.

Results : Her development quotient was found to be 46, plasma ammonia and lactate levels were normal, creatinine kinase was high (314 IU/L). MRI of brain revealed polymicrogyria, white matter changes and subcortical cerebellar cysts. The pattern recognition of MR imaging features may serve as a clue to the diagnosis of alpha dystroglycanopathy although definite diagnosis could be obtained only by muscle biopsy and genetic testing.

Conclusion : In Japan, Fukuyama disease is fairly common, second to Duchenne muscular dystrophy but milder form lie this case is rare. The mutation in FKTN gene which gives instructions for making a protein called fukutin, which chemically modify a protein alpha-dystroglycan. High index of suspicion and early diagnosis is required to initiate prompt therapy which is mainly supportive with rigorous physiotherapy, antiepileptic drugs, parental and genetic counseling. 
Introduction : Alpha dystroglycanopathies are heterogeneous group of disorders and a subgroup of these patients has characteristic brain imaging findings. The clinical features include global developmental delay, contractures, hypotonia and oculomotor abnormalities in all. Other common findings are consanguinity, seizures, macrocephaly or microcephaly, retinal changes and hypogenitalism in majority of patients. ${ }^{1,2}$

Case Vignette : A four year old girl presented in the OPD with history of delayed developmental milestones, irritability, history of throwing tantrums and anger outbursts with decreased appetite. She was admitted in paediatric neurology IPD with complex partial seizure with secondary generalization. She was born full term of non-consanguineous marriage by LUCS. It was a valuable pregnancy following primary infertility, six years after marriage. She cried just after birth and there was no significant perinatal insult. There was no regression of developmental milestones. The family history is negative up to three generations. The clinical features included squint, microcephaly (Head circumference below 2 Standard deviations as per age and ethnicity standards) with delayed developmental milestones and complex partial seizure.

\section{CLINICAL AND INVESTIGATION FINDINGS :}

On examination, she was found afebrile. Her clinical findings and investigation findings are summarized in Table 1 and Table 2.

\section{Table 1 : Clinical features and systemic examination findings of the patient}

\begin{tabular}{|l|l|}
\hline Temperature & 98.2 degree F, afebrile \\
\hline CVS & $\begin{array}{l}\text { S1, S2 heard, no murmurs, all peripheral pulses } \\
\text { were equally felt without any bruit. }\end{array}$ \\
\hline Respiratory system & $\begin{array}{l}\text { Vesicular breath sounds were present, no added } \\
\text { sounds. }\end{array}$ \\
\hline CNS & No Hepatospleenomegaly \\
\hline & $\begin{array}{l}\text { She was alert, conscious and active. } \\
\text { Pupils found 3 mm in diameter and reacting. } \\
\text { Mild convergent squint. } \\
\text { Fundus was found to be normal. } \\
\text { No gross abnormalities were found on motor } \\
\text { system examination. There was no atrophy, } \\
\text { hypertrophy but there was mild spasticity in all } \\
\text { four limbs. } \\
\text { Power was grossly normal. } \\
\text { Deep tendon reflexes were brisk in both upper } \\
\text { and lower limbs. } \\
\text { Plantar was bilaterally flexor. } \\
\text { Sensory system examination doesn't reveal any } \\
\text { abnormalities. } \\
\text { Extrapyramidal system- no abnormality } \\
\text { was detected. } \\
\text { Cerebellar signs- absent. }\end{array}$ \\
\hline
\end{tabular}




\begin{tabular}{|l|l|}
\hline Opthalmological findings & $\begin{array}{l}\text { Good visual tracking. } \\
\text { Normal anterior segment. } \\
\text { Normal fundus. }\end{array}$ \\
\hline Dermatological findings & $\begin{array}{l}\text { Nothing significant which rules out Junctional } \\
\text { epidermolysis bullosa. }\end{array}$ \\
\hline DQ (Development quotient) & 46 \\
\hline
\end{tabular}

\section{Table 2 : The investigation findings of the patient}

\begin{tabular}{|c|c|}
\hline Routine Complete haemogram & $\begin{array}{l}\mathrm{Hb} 11.3 \mathrm{gm} / \mathrm{dl} . \mathrm{TLC}=477 . \mathrm{N} 55, \mathrm{bE} 02, \mathrm{~B} 00, \mathrm{~L} 42 \text {, } \\
\mathrm{M} 01, \mathrm{ESR}=10 . \mathrm{PCV}=32.0, \mathrm{MCV}=88.0, \mathrm{MCH} \\
\text { 31.0, MCHC=35.0. RBC=3.6 million, Platelet } \\
\text { count=2.2. lakhs. PBS=No abnormal cells has } \\
\text { been noted. }\end{array}$ \\
\hline Plasma ammonia & 40 (10-65 micromol/L) \\
\hline Plasma lactate & $\begin{array}{l}16.3(4.5 \text { to } 19.8 \mathrm{mg} / \mathrm{d}) \text { rules out MELAS } \\
\text { (although normal lactic acid doesn't rule } \\
\text { out MELAS unless there is very high CNS } \\
\text { involvement. }\end{array}$ \\
\hline Urine for abnormal metabolites & $\begin{array}{l}\text { Not found (rules out storage and urea cycle } \\
\text { disorders). }\end{array}$ \\
\hline Serum creatinine kinase & $314 \mathrm{IU} / \mathrm{L}$ \\
\hline EEG & Non specific slowing of waves was found. \\
\hline MRI brain & $\begin{array}{l}\text { Bilateral fronto-parietal polymicrogyria and } \\
\text { tempero-occipital pachygyria with white matter } \\
\text { changes has been noted. } \\
\text { Cystic changes in cerebellum predominantly } \\
\text { in the vermis suggestive of Alpha- } \\
\text { Dystroglycanopathy. }\end{array}$ \\
\hline Echocardiography & $\begin{array}{l}\text { Normal valves and chambers. } \\
\text { Normal LV function. } \\
\text { No obvious shunt lesion }\end{array}$ \\
\hline
\end{tabular}

\section{Clinical diagnosis}

Early infantile hypotonia with progressive weakness.

Contractures of hip, knees, interphalangeal joints.

Myopathic facial appearance

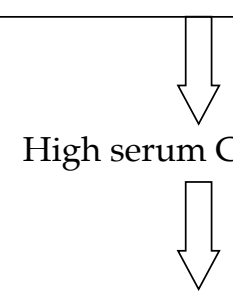




\section{Neuroimaging MRI}

Pachygyria in tempero-parietal-occipital region

Dilated lateral ventricle

Pontine hypoplasia

Delayed myelination and hyper intensities in T2 MRI.

Cerebellar cysts.

Discussion : The differential diagnoses made at this stage were (1) Congenital Myopathies, (2) Dystrophinopathies, (3) Emery-Dreifuss Muscular Dystrophy, (4) Metabolic Myopathies, (5) Limb-Girdle Muscular Dystrophy, (6) Spinal Muscular Atrophy, (7) Charcot-Marie-Tooth disease (CMT), (8) Congenital myasthenia etc. But the characteristic MRI findings and raised CPK levels favour the diagnosis of alpha dystroglycanopathy, the Fukuyama congenital muscular dystrophy (milder variant); itself rare, milder form is more uncommon. In major variant the $\mathrm{CK}$ level can raise upto 2000-4000 IU/L, here only $314 \mathrm{IU} / \mathrm{L}$. However in Japan, Fukuyama disease is fairly common occurring in approximately $50 \%$ of cases. ${ }^{5.6,7}$

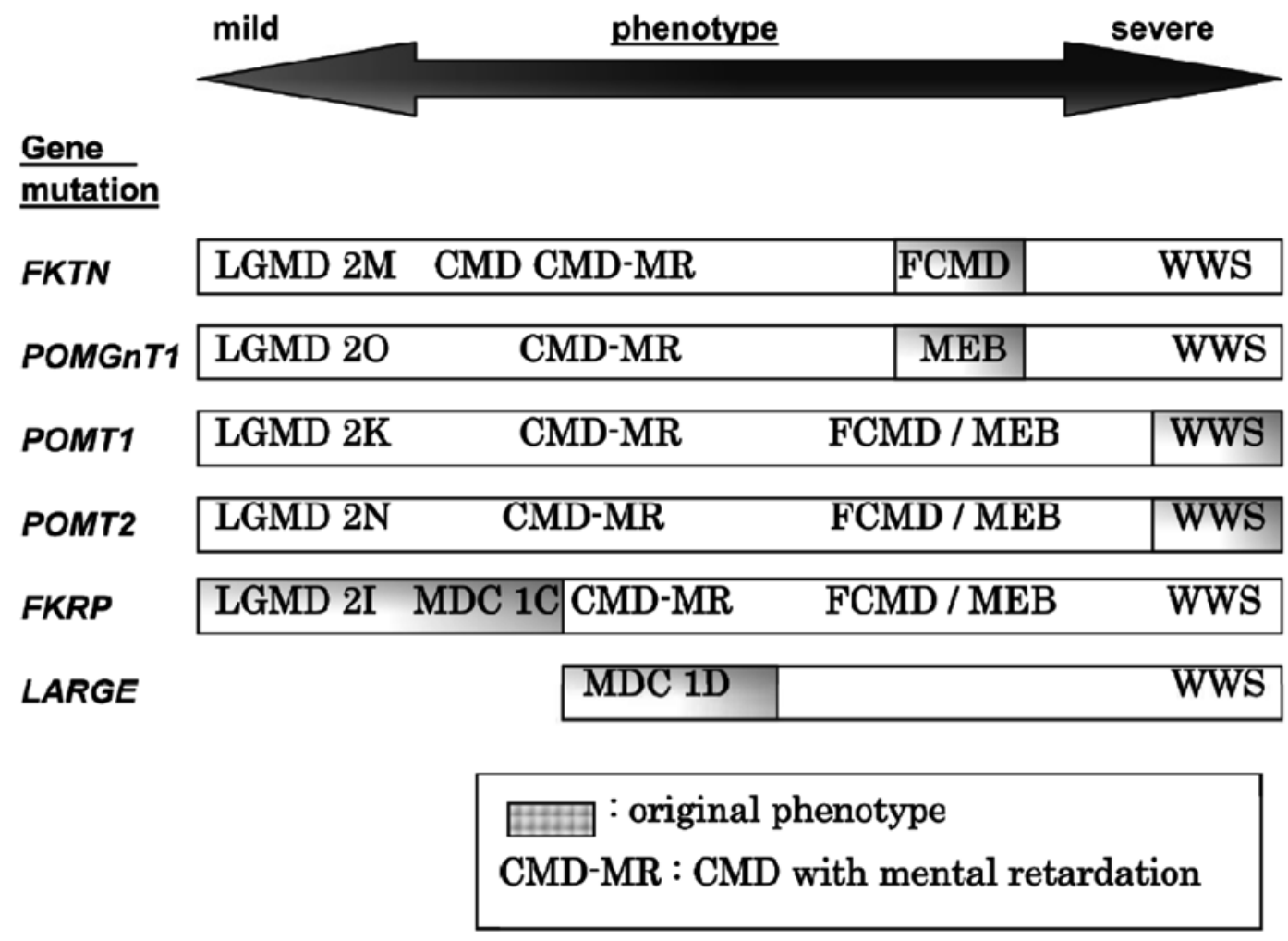

Fig. 4 : Genetic mutation and clinical phenotypes of alpha-dystroglycanopathies. ${ }^{8,9,10}$

The individuals with Ullrich congenital muscular dystrophy has rigid spine with muscular dystrophy (deficiency of selenoprotein $\mathrm{N}$ ), and integrin- $\alpha 7$ deficiency. The creatine kinase (CK) levels are normal to mildly elevated ( $\leq 5$ times normal). High CK levels (more than 1000) are found in patients with congenital muscular dystrophy with familial junctional epidermolysis bullosa. CK levels are 
mildly to markedly elevated (2-150 times normal) in patients with congenital muscular dystrophy due to abnormal glycosylation or with laminin- $\alpha 2$ mutations (alpha dystroglycanopathy). NCS results are abnormal only in some cases with mutations in laminin- $\alpha 2$, where mild neuropathic changes may be seen. EMG usually shows typical small-amplitude, narrow-duration motor-unit potentials with early recruitment. Prenatal diagnosis had been performed mostcommonlyinfamilies withmutationsinlaminin$\alpha 2$ which is expressed in 9-week trophoblasts, in part, because this is the most common congenital muscular dystrophy. Linkage analysis can also be performed but is also at times unreliable, especially in families with partial laminin- $\alpha 2$ deficiency or no brain MRI abnormalities. Muscle biopsy is indicated to confirm the diagnosis and exclude other causes of weakness.In complete laminin- $\alpha 2$ deficiency patients may have severe dystrophic pathology with muscle-fiber degeneration and regeneration, fiber necrosis, and endomysial and perimysial fibrosis. Immunohistochemical studies show complete loss of staining for laminin- $\alpha 2 .^{11,12,13}$

\section{Table 3 : Differential diagnosis of the patient. ${ }^{14-17}$}

\section{Congenital muscular dystrophy with laminin-alpha2 deficiency (MDC1A, classic CMD, merosin-deficient CMD).}

Most common form (40\%) of all cases.May have severe hypotonia, weakness, feeding difficulties, mild intellectual disability and seizure in $30 \%$ cases. Periventricular hypomyelination

\section{Integrin-alpha7 deficiency}

Very rare, presents with hypotonia in infancy with delayed motor milestones. One patient has been followed longitudinally and required noninvasive ventilation at age 8 years and became wheelchair bound at age 12 years.

\section{Congenital muscular dystrophy with rigid spine (RSMD1).}

Variable degrees of proximal muscle weakness with hypotonia have been noticed. Carries better prognosis, except few, most patients can eventually walk. In contrast to Ullrich congenital muscular dystrophy, contractures are not present at birth, but they usually develop at age 3-10 years.

The most characteristic pattern is spinal rigidity and scoliosis. Contractures of the face, proximal limbs, and finger extensors may also be present.

Respiratory insufficiency is common and progressive and may be more severe than limb weakness.

Muscle weakness is slowly progressive, no cardio-vascular or MRI abnormalities. Intelligence found normal.

\section{Ullrich congenital muscular dystrophy.}

Presents with hypotonia, kyphosis, joint contractures, toticollis, facial dysmorphism. But intellectual ability remains preserved and there are no MRI abnormalities.

4. Congenital muscular dystrophy with familial junctional epidermolysis bullosa.[2]

Can become severe with blistering lesions and can cause death. Proximal muscle weakness (wheel chair bound) and myesthenic symptoms has been described and may respond to pyridostigmine.

\section{Fukuyama congenital muscular dystrophy} (mutation in fukutin).

Poor sucking, weakness, lack of head control are commonly found.. Most patients can walk, progressive weakness and respiratory distress occurs. Cardiac involvement with cardiomyopathy and CCF appears after 10 years.

Mild ocular abnormalities, with poor pursuits and strabismus. Can cause retinal detachment, cataracts, severe myopia. Crebellar cysts seen and seizure occur about $50 \%$ patients. 


\section{LMNA-deficient CMD.}

Laminin mutation, mostly present with CMD (Congenital muscular dystrophy) with rigid spine.

\section{Muscle-eye-brain (MEB) disease.}

Occurs due to genetic mutations. Eye abnormalities and genetic changes are similar to Fukuyama's disease.

\section{MANAGEMENT}

No specific treatment is available for any of the congenital muscular dystrophies. Aggressive supportive care is essential to preserve muscle activity, to allow for maximal functional ability, and to prolong the patient's life expectancy. The primary neuromuscular concerns include prevention and correction of skeletal abnormalities, such as scoliosis, foot deformities, and contractures, to maintain ambulation. Aggressive use of passive stretching, bracing, and orthopedic procedures, such as spinal fusion, allows the patient to remain independent for as long as possible. Pulmonary complications are the other main concern. Early monitoring and intervention to treat respiratory insufficiency is important because effective therapies can help to improve function and prolong life expectancy. Such therapies include noninvasive bilevel positive airway pressure and/or continuous positive airway pressure or permanent ventilation via a tracheostomy. Cardiac complications are especially common in patients with a mutation in FKRPand occasionally in patients with laminin- $\alpha 2$ deficiency. Treatment of dilated cardiomyopathy with ACE inhibitors and beta-blockers may be necessary. Children with congenital muscular dystrophy may have other neurologic treatment issues, including seizure management, need for supplementary gastric tube feedings, ophthalmologic care, and general medical concerns that occur in profoundly retarded children. As with other hereditary myopathies, a team approach, including a neurologist, pulmonologist, ophthalmologist, cardiologist, orthopedic surgeon, physical medicine specialist, orthotist, and counselors, is required to ensure the best possible care. In patients with CMD with familial junctional epidermolysis bullosa besides the above standard measures, management must include supportive care to protect the skin from blistering, appropriate dressings, and prevention of secondary infections. Activities should minimize skin trauma. Orthopedic surgery is often necessary in patients who live several years with their disease to prevent contractures and scoliosis. According to evidence-based guidelines from the American Academy of Neurology, multidisciplinary care by experienced teams is important for diagnosing and promoting the health of children with $\mathrm{CMD}^{[51]}$ Patients with alpha-dystroglycanopathies may require prolonged hospitalization. For example, neonates or infants may have progressive disease and have feeding difficulties, cardiopulmonary complications, seizures, or profound mental retardation. Consultation with at least (however not limited to) with the following may prove helpful which (1) Ophthalmologist, (2) Pulmonologist, (3) Cardiologist, (4) Orthopedic surgeon, (5) Epileptologist, (6) Physical and rehabilitation medicine specialist and (7) Dermatologist (patients with CMD with familial junctional epidermolyis bullosa). Older children may need admission for orthopedic care or cardiopulmonary complications. (a) feeding difficulties, (b) respiratory failure, (c) seizures, (d) contractures and/or scoliosis and (e) Blindness. severe disease, such as WalkerWarburg syndrome, patients usually die within the first few years of life. In congenital muscular dystrophy with laminin- $\alpha 2$ deficiency and in some cases of mutations in FKRP, patients occasionally have a relatively normal life span. ${ }^{18-20}$

\section{CONCLUSION}

Most FCMD patients are intellectually disabled and the level is moderate to severe, with IQs ranging from 30 to 50 . In a recent study, $62 \%$ of patients developed seizures. Among them, $71 \%$ had only 
febrile seizures, $6 \%$ had afebrile seizures from the onset, and $22 \%$ developed afebrile seizures following febrile seizures. Most patients had seizures that were controllable with just 1 type of antiepileptic drug, but $18 \%$ had intractable seizures that must be treated with 3 medications. The prognosis depends on the type of congenital muscular dystrophy. The Genetic counseling is often helpful to patients and their families to assist in family planning. ${ }^{21}$

\section{REFERENCES}

1. Akiyama T, Ohtsuka $\mathrm{Y}$, Takata T, Hattori J, Kawakita Y, Saito K. The mildest known case of Fukuyama-type congenital muscular dystrophy. Brain Dev. 2006 Sep. 28(8) : 537-40. [Medline].

2. Sparks SE, Escolar DM. Congenital muscular dystrophies. Handb Clin Neurol. 2011. 101 : 47-79. [Medline].

3. Pagon RA, Adam MP, Ardinger HH, et al., editors. Gene Reviews ${ }^{\circledR}$ [Internet]. Seattle (WA): University of Washington, Seattle; 1993-2016.

4. http://www.ncbi.nlm.nih.gov/books/NBK1206/figure/ fcmd.F1/?report=objectonly last accessed on 10/07/2016

5. Fukuyama Y, Kwazura M, Haruna H. A peculiar form of congenital muscular dystrophy. Paediatr Univ Tokyo. 1960. 4 :5-8.

6. Mercuri E, Muntoni F. The ever-expanding spectrum of congenital muscular dystrophies. Ann Neurol. 2012 Jul. 72(1) : 9-17. [Medline].

7. Graziano A, Bianco F, D'Amico A, Moroni I, Messina S, et al. Prevalence of congenital muscular dystrophy in Italy : a population study. Neurology. 2015 Mar 3. 84 (9) : 904-11. [Medline].

8. Geranmayeh F, Clement E, Feng LH, et al. Genotypephenotype correlation in a large population of muscular dystrophy patients with LAMA2 mutations. Neuromuscul Disord. 2010 Apr. 20(4) : 241-50. [Medline].

9. Bonnemann CG. The collagen VI-related myopathies: muscle meets its matrix. Nat Rev Neurol. 2011 Jun 21. 7(7) : 379-90. [Medline].

10. Nakashima H, Kibe T, Yokochi K. Congenital muscular dystrophy caused by integrin alpha7 deficiency'. Dev Med Child Neurol. 2009 Mar. 51(3) : 245. [Medline].
11. Gundesli H, Talim B, Korkusuz P, et al. Mutation in exon $1 \mathrm{f}$ of PLEC, leading to disruption of plectin isoform 1f, causes autosomal-recessive limb-girdle muscular dystrophy. Am J Hum Genet. 2010 Dec 10. 87(6) : 834-41. [Medline].

12. Schara U, Kress W, Bonnemann CG, et al. The phenotype and long-term follow-up in 11 patients with juvenile selenoprotein N1-related myopathy. Eur J Paediatr Neurol. 2008 May. 12(3) : 224-30. [Medline].

13. Schoenmakers E, Agostini M, Mitchell C, et al. Mutations in the selenocysteine insertion sequence-binding protein 2 gene lead to a multisystem selenoprotein deficiency disorder in humans. J Clin Invest. 2010 Dec 1. 120(12) : 4220-35. [Medline]. [Full Text].

14. Yiu EM, Klausegger A, Waddell LB, et al. Epidermolysis bullosa with late-onset muscular dystrophy and plectin deficiency. Muscle Nerve. 2011 Jul. 44(1) : 135-41. [Medline].

15. MitsuhashiS,OhkumaA,TalimB,etal.Acongenitalmuscular dystrophy with mitochondrial structural abnormalities caused by defective de novo phosphatidylcholine biosynthesis. Am J Hum Genet. 2011 Jun 10. 88(6) : 845-51. [Medline]. [Full Text].

16. Clarke NF, Maugenre S, Vandebrouck A, et al. Congenital muscular dystrophy type 1D (MDC1D) due to a large intragenic insertion/deletion, involving intron 10 of the LARGE gene. Eur J Hum Genet. 2011 Apr. 19(4) : 452-7. [Medline].

17. van Reeuwijk J, Grewal PK, Salih MA, et al. Intragenic deletion in the LARGE gene causes Walker-Warburg syndrome. Hum Genet. 2007 Jul. 121(6) : 685-90. [Medline].

18. Messina S, Tortorella G, Concolino D, et al. Congenital muscular dystrophy with defective alpha-dystroglycan, cerebellar hypoplasia, and epilepsy. Neurology. 2009 Nov 10. 73(19) : 1599-601. [Medline].

19. Vuillaumier-Barrot S, Bouchet-Séraphin C, Chelbi M, et al. Identification of mutations in TMEM5 and ISPD as a cause of severe cobblestone lissencephaly. Am J Hum Genet. 2012 Dec 7. 91(6) : 1135-43. [Medline]. [Full Text].

20. Cirak S, Foley AR, Herrmann R, et al. ISPD gene mutations are a common cause of congenital and limb-girdle muscular dystrophies. Brain. 2013 Jan. 136 : 269-81. [Medline]

21. Ishigaki K. Central Nervous Involvement in Patients with Fukuyama Congenital Muscular Dystrophy. Brain Nerve. 2016 Feb; 68(2) : 119-27. 